\title{
Review \\ Noncommunicable diseases among the Bahraini population: a review
}

R.R. Hamadeh'

SUMMARY The review investigates changes in the morbidity and mortality due to noncommunicable diseases in the Bahraini population and looks at the conditions which may have contributed to them in the 1980 s and $1990 \mathrm{~s}$. Data were extracted from the Ministry of Health annual health reports and the 1981 and 1991 censuses and other relevant published papers. Government strategies for the control of noncommunicable diseases and the promotion of healthy lifestyles are outlined.

\section{Introduction}

The Public Health Directorate is the main preventive service in Bahrain. Primary care is provided by the government through 19 health centres and 2 clinics. Secondary care is provided by the government at 2 general hospitals, 5 matemity hospitals, 1 psychiatric hospital and 1 geriatric hospital [I]. In addition, there are 3 private hospitals and several private clinics in the country.

Death registration is mandatory in Bahrain and deaths are certified usually without performing an autopsy. A 1993 study examining the validity and reliability of death certificates showed that the level of consistency between the stated cause of death on death certificates and the diagnosis based on hospital records compared to reviewers' diagnoses to be $76 \%$, with a test bias ratio of 1.2 and a positive likelihood ratio of 2.7 [2]. Moreover, there has been a reduction in the proportion of conditions where the cause of death was classified as ill defined [3]. In the absence of detailed information on the conditions of outpatients, hospital discharges from the main. general hospital, Salmaniya Medical Complex (SMC), offer the best data source on morbidity in the country, as SMC deals with $90 \%$ of total hospital inpatients [3]. Causes of morbidity and mortality are currently coded using the 9 th revision of the International classification of diseases.

Bahrain has undergone rapid economic development since the 1970s. This development has been paralleled by changes to a more sedentary lifestyle and westernized diet [4-6]. and by increased cigarette consumption [7].

The aim of this review was to investigate changes in the morbidity and mortality due to noncommunicable diseases (NCDs) in the Bahraini population and to focus on the conditions that may have contributed to them in the 1980s and 1990s. Non-Bahrainis were excluded due to their transient nature. Annual health reports published by the Ministry of Health [8] for the period 1982-97, and the 1981 and 1991 censuses

${ }^{\top}$ Department of Family and Community Medicine, College of Medicine and Medical Sciences, Arabian Gulf University, Bahrain.

Received: 16/11/99; accepted: 20/04/00

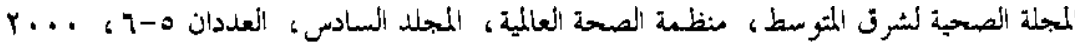


[9] were reviewed. In the annual reports, the main causes of death and hospital discharges are presented by major disease groups for Bahrainis and non-Bahrainis [8]. Thus, it was not possible to examine specific causes of death and morbidity. The prevalence of certain conditions and lifestyle patterns like diabetes, hypertension, obesity, smoking, physical activity and intake of fruits and vegetables were abstracted from all available locally and internationally published papers.

\section{Sociodemographic characteristics}

The 1997 population of Bahrain was estimated to be 620378 , of whom $61.2 \%$ were Bahraini [10]. The Bahraini population is almost equally distributed by sex in each age group. The Bahraini male and female populations have evidenced a small but steady increase in the older age groups since the 1980s. Adult literacy rates increased from $74.8 \%$ and $51.9 \%$ in males and females respectively in 1981 to $86.7 \%$ and $71.3 \%$ in males and females respectively in 1991 . Between the 1981 and 1991 censuses respectively, labour force participation increased in men aged 15-65 years from $77.8 \%$ to $80.9 \%$ and in women from $14.3 \%$ to $18.7 \%$ [9].

\section{Mortality}

Deaths in those under 50 years in the Bahraini population decreased frum $43.0 \%$ in 1982 to $24.2 \%$ in 1997 . Females showed a sharper decline than males in this age group, reaching less than half the rate of 1982 (from $45.1 \%$ to $21.0 \%$ ). A change has occurred in the proportional mortality ratios (PMR) of some causes of death in the Bahraini population between 1982 and

Table 1 Proportional mortality ratio (\%) by sex and cause of death, Bahraini population, 1982" and $1997^{\circ}$

\begin{tabular}{lrrrrrr}
\hline Cause of death & \multicolumn{2}{c}{ Males } & \multicolumn{2}{c}{ Females } & \multicolumn{2}{c}{ Total } \\
& 1982 & $\mathbf{1 9 9 7}$ & 1982 & 1997 & 1982 & 1997 \\
\hline Infectious arid parasitic diseases & 2.1 & 2.3 & 2.4 & 2.2 & 2.3 & 2.3 \\
Neoplasms & 11.0 & 14.8 & 7.1 & 11.5 & 9.4 & 13.4 \\
Endocrine, nutritional, and metabolic & & & & & & \\
$\quad$ and immunity disorders & 3.3 & 7.7 & 4.9 & 9.7 & 3.9 & 8.6 \\
Diseases of the circulatory system & 31.0 & 30.5 & 34.0 & 37.3 & 32.2 & 33.3 \\
Diseases of the respiratory system & 6.6 & 8.6 & 6.3 & 7.5 & 6.4 & 8.1 \\
Diseases of the digestive system & 2.5 & 5.7 & 2.7 & 5.9 & 2.6 & 5.8 \\
Diseases of the genitourinary system & 2.5 & 4.9 & 3.3 & 3.8 & 2.8 & 4.4 \\
Pertnatal conditions & 13.5 & 2.9 & 14.9 & 2.1 & 14.1 & 2.6 \\
Injury and poisoning & 10.6 & 5.5 & 6.8 & 4.1 & 9.0 & 4.9 \\
Other & 4.4 & 8.3 & 8.4 & 8.4 & 6.1 & 8.4 \\
Unknown causes & 12.5 & 8.8 & 9.2 & 7.5 & 11.2 & 8.2 \\
\hline
\end{tabular}

Annual Report 1982. Bahrain, Office of Health Information System, Ministry of Health, 1983. Health Statistics 1990-97. Bahrain, Publlcalions Group, Health information Directorate, Ministry of Health,
1998 . 
1997. Neoplasms, diseases of the respiratory, digestive and genitourinary systems and endocrine, nutritional and immunity disorders increased in males, females and both sexes combined among the Bahraini population, while the PMR due to perinatal conditions, injury and poisoning and unknown causes declined (Table 1). The PMR due to neoplasms increased in both male and female Bahrainis. The percentage change in the PMR due to neoplasms for the period 1982-97 in females was twice that of males ( $62 \%$ compared to $34.5 \%)$.

Cancer has been the second most common cause of death in Bahraini males and females since the mid-1990s, whereas in the 1980s it ranked fourth. Deaths due to circulatory diseases remained stable in males and females combined but increased slightly in females. Circulatory diseases accounted for one-third of the deaths in Bahraini males, females and both sexes combined and occupied the first rank as a cause of death throughout the period. The PMR due to infectious and parasitic diseases, diseases of the respiratory system, perinatal conditions and maternal causes are similar to those for industrialized countries [11].

\section{Morbidity}

Circulatory diseases ranked fourth and neoplasms eleventh in total Bahraini inpatient discharges from the SMC in 1997. The percentage of inpatient discharges diagnosed as circulatory diseases slightly declined in males and females during 1992-97 (Table 2). Bahraini females showed a $24 \%$ increase in neoplasms and Bahraini males a $9.5 \%$ decrease during the same period (Table 2).

From preliminary data of the Bahrain Cancer Registry, haematopoeitic and reticuloendothelial cancers, cancer of the female breast, colorectal cancer, stomach cancer, lung cancer and cancers of the urinary bladder, lip, oral cavity, pharynx, thyroid, cervix and ovary are the most frequent cancers among Bahrainis. Smoking and diet-associated cancers have been found to account for not less than $60 \%$ of all cancers in the Bahraini population [12].

Diabetes is common in the Bahraini population (Table 3 ). The prevalence of diabetes (based on World Health Organization criteria) among adult males ( $\geq 20$ years old) is $26.4 \%$, which is roughly the same as to that of adult females $(25.0 \%)$ [13].

Table 2 Percentege change In discharges from the Salmaniya Medical Complex due to neoplasms and diseases of the circulatory system, Bahraini population, 1992-97

\begin{tabular}{|c|c|c|c|c|c|c|}
\hline Yeer & $\begin{array}{c}\text { Diseases } \\
\text { Males }\end{array}$ & $\begin{array}{l}\text { the circula } \\
\text { Females }\end{array}$ & $\begin{array}{l}\text { y system } \\
\text { Total }\end{array}$ & Males & $\begin{array}{c}\text { Neoplasms } \\
\text { Females }\end{array}$ & Tota \\
\hline 1992 & 11.0 & 6.7 & 8.4 & 4.2 & 2.5 & 3.2 \\
\hline 1993 & 10.4 & 6.0 & 7.7 & 3.7 & 2.5 & 3.0 \\
\hline 1994 & 11.4 & 6.3 & 8.3 & 4.1 & 3.3 & 3.6 \\
\hline 1995 & 9.7 & 5.5 & 7.2 & 3.9 & 3.7 & 3.8 \\
\hline 1996 & 9.0 & 5.7 & 7.1 & 4.1 & 3.0 & 3.5 \\
\hline 1997 & 9.3 & 5.4 & 7.0 & 3.8 & 3.1 & 3.4 \\
\hline$\%$ change & -15.5 & -19.4 & -16.7 & -9.5 & 24.0 & 6.3 \\
\hline
\end{tabular}

المجلة الصحية لشرق المثوسط، منظمة الصحة العالمية، المجلد السادس، العددان ه-ب، ... 
Table 3 Prevalence of diabetes among the Bahraini population by age group

\begin{tabular}{lcccc}
\hline $\begin{array}{l}\text { Age } \\
\text { (years) }\end{array}$ & Yea & \multicolumn{2}{c}{$\begin{array}{c}\text { Prevalence (\%) } \\
\text { Males }\end{array}$} & source \\
Females & \\
\hline $40-49$ & $1995-6$ & 22.9 & - & {$[14]^{\mathrm{a}}$} \\
$50-59$ & $1995-6$ & 29.6 & 35.4 & {$[14]$} \\
$60-69$ & $1995-6$ & - & 37.6 & {$[14]$} \\
$30-49$ & 1992 & 0.3 & 6.6 & {$[17]^{\mathrm{b}}$} \\
$50-79$ & 1992 & 6.4 & 19.8 & {$[17]$} \\
$\geq 20$ & 1996 & 26.4 & 25.0 & {$[13]^{\mathrm{a}}$} \\
$\geq 50$ & 1995 & 14.0 & 19.0 & {$[16]^{\mathrm{b}}$} \\
$\geq 65$ & 1992 & 10.2 & 15.0 & {$[15]^{\mathrm{b}}$} \\
\hline
\end{tabular}

-Based on clinical and laboratory diagnosis.

'Self-reported.

Table 4 Prevalence of overweight and obesity among adult Bahrainis

\begin{tabular}{|c|c|c|c|}
\hline Population & $\begin{array}{r}\text { Yeer } \\
\text { Or }\end{array}$ & $\begin{array}{l}\text { Prevaler } \\
\text { ferwelght" }\end{array}$ & $\begin{array}{l}\text { Obe }(\%) \\
\text { Obesity }\end{array}$ \\
\hline $20-65$ years & $1991-92^{c}$ & & \\
\hline Males & & 26.3 & 16.0 \\
\hline Females & & 29.4 & 31.4 \\
\hline $30-49$ years & $1992^{\circ}$ & & \\
\hline Males & & 42.4 & 25.6 \\
\hline Females & & 32.2 & 47.1 \\
\hline $50-79$ years & $1992^{\circ}$ & & \\
\hline Males & & 31.2 & 17.9 \\
\hline Females & & 29.5 & 50.5 \\
\hline Totar & $1992^{\circ}$ & & \\
\hline Males & & 35.9 & 21.2 \\
\hline Females & & 31.0 & 48.6 \\
\hline $15-21$ years & $1989^{0,1}$ & & \\
\hline Males & & 15.6 & - \\
\hline Females & & 17.4 & - \\
\hline
\end{tabular}

"Body mass index $=25-29.9 \mathrm{~kg} / \mathrm{m}^{2}$.

Boody mass index $\geq 30 \mathrm{~kg} / \mathrm{m}^{2}$.

'Source: [18].

oSource: [17].

-Source: [19].

'Ovenweight or obese $\left(B M />25 \mathrm{~kg} / \mathrm{m}^{2}\right)$.
However, in the age group 50-59 years, women have a higher prevalence of diabetes $(35.4 \%)$ than men $(29.6 \%)$ [14]. Other studies that relied on self-reporting have also shown diabetes to be more prevalent among older women than men [15-17].

In older Bahrainis ( $\geq 50$ years of age), the reported prevalence of hypertension in women $(27.0 \%)$ is almost double that of men $(15.0 \%)[16,17]$. In a recent study, $55 \%$ of women aged $50-69$ years had hypertension (systolic pressure $\geq 140 \mathrm{mmHg}$, diastolic pressure $\geq 90 \mathrm{mmHg}$ ) [14]. In the same study, the prevalence of hypertension was found to be $41.5 \%$ in men aged $40-59$ years.

\section{Lifestyle patterns}

Several studies have shown that obesity, i.e. a body mass index $(B M I) \geq 30 \mathrm{~kg} / \mathrm{m}^{2}$, is a public health problem among nationals in Bahrain $[15,17,18]$. The prevalence of obesity among females is higher than that of males in all age groups. Overweight (BMI of $25-29.9 \mathrm{~kg} / \mathrm{m}^{2}$ ) was found to be slightly more common among males than females $[17,19]$, except in one study $[18]$ where the prevalence was slightly lower in males $(26.3 \%)$ than females $(29.4 \%)$ (Table 4).

The prevalence of cigarette smoking, other types of smoking and all types combined declined in the adult male Bahraini population in the 1990s compared to the 1980 s $[7,16]$. Moreover, the prevalence of smoking among males in the general Bahraini adult population [16], in primary health care physicians [20], in medical students [21] and in secondary-school students [22] was found to be similar (Table 5 ). It is worth noting that the prevalence of smoking among male secondary-school students increased in the 1990s compared 
Table 5 Prevalence of 8 moking in different Bahraini population groups

\begin{tabular}{|c|c|c|c|}
\hline Study & Study & Preve & ance $(\%)$ \\
\hline period & population & Males & Females \\
\hline $1995^{a}$ & $\geq 15$ years & 25.3 & 9.3 \\
\hline $1994^{\circ}$ & $\begin{array}{l}\text { Primary health } \\
\text { care physicians }\end{array}$ & 22.7 & 6.3 \\
\hline $1992^{\circ}$ & Medical students & 25.0 & 0.0 \\
\hline $1996^{\circ}$ & $\begin{array}{l}\text { Secondary-school } \\
\text { students }\end{array}$ & 25.8 & - \\
\hline
\end{tabular}

Source: [46].

"Source: [20].

source: [21].

'Source: [22].

to the early 1980 s [22-24]. There was almost no change in the prevalence of daily smoking among light ( $<1$ packet/day) and heavy ( $\geq 1$ packet/day) male cigarette smokers [25]. Similar findings were noted for male smokers of other tobacco and for all types of smoking combined [25]. The prevalence of cigarette smoking (daily and occasional) and daily smoking of all types of tobacco increased in adult females $[7,16,25]$. The increase (100\%) was highest among daily cigarette smokers [25].

A higher percentage of Bahraini men aged $30-79$ years reported engaging in exercise compared to their female counterparts (12.7\% and $8.3 \%$ respectively) [17]. A very low percentage of Bahraini women (1.3\%) aged 50-69 years old were reported to be active at leisure time (leisure time expenditure $>0.3 \mathrm{MJ} /$ day) [14]. A similar percentage of men and women (30-79 years old) reported daily intake of fruits (63.5\% and $65.4 \%$ respectively) and vegetables $(78.9 \%$ and $81.1 \%$ respectively) [17].

\section{Control of noncommunicable diseases}

The government has undertaken several strategies to control NCDs. Cancer, circulatory and cardiovascular diseases and diabetes are among the 11 "priority areas for health gain" identified by the Ministry of Health. A health planning committee has been established for each of these priority areas. The main function of these committees is to develop strategic goals in each priority area.

For cancer, strategies include the use of the National Cancer Register to analyse causes and manage cases of cancer, to promote healthy lifestyles, develop and support the use of cancer screening programmes for cervical and breast cancer and to exploit the latest technology available at SMC to treat cancers as early as possible. For cardiovascular diseases, the main strategies are: establishment of a registry and using it to analyse cause and manage cases; promotion of healthy lifestyles; enhancement of coordination between facilities at SMC and the Bahrain Defence Force Hospital (the other general government hospital); and formation of links with experienced international institutions. Strategies for diabetes include establishment of baseline information about the prevalence of diabetes, implementation of a systematic health care programme for diabetics and implementation of a rigorous and systematic health education programme [3].

Tobacco control is carried out through legislation and health education in Bahrain [25]. With regards to nutrition, the Ministry of Health recently introduced guidelines for the advertising of milk substitute products [3].

NCD-related health education programmes target the general public and special groups and include education on the 
hazards of smoking, and the promotion of a healthy diet and healthy lifestyle. The government also provides prompt early admission to the coronary care unit and up-to-date treatment of circulatory diseases, diabetes and cancer. Ongoing training of professionals and nonprofessionals is another of the strategies of the Ministry of Health. The country also has governmental and nongovernmental committees and societies that aim to control NCDs.

\section{Recommendations}

Efforts to strengthen programmes that aim to combat smoking and control obesity, diabetes and hypertension should continue. Preventive efforts need to focus on women because of the high prevalence of contributing factors for NCDs among them and because of their roles as mothers and educators. There is a need for education programmes to raise the awareness of women of the importance of physical exercise and of husbands to support their wives in allocating time for it. In smoking control, greater attention should be given to young people, particularly middle- and secondaryschool males. Policies and ongoing programmes that promote health education and healthy lifestyles should continue to be encouraged and supported. Early detection and efficient management of circulatory diseases, neoplasms, diabetes and hypertension should continue to be a priority. Planning of baseline studies on risk factors of NCDs where data are lacking, such as serum cholesterol levels, are of prime importance. Moreover, studies to assess changes in the contributing factors for NCDs and evaluation of ongoing control programmes should continue. Given the attention and concerted efforts NCDs are receiving in Bahrain, monitoring and follow-up of the policies and programmes are vital in order to ensure the burden these diseases incur is reduced.

\section{References}

1. Health statistics 1998. Bahrain, Health Information Diroctorato, Ministry of Health, 1999.

2. Al-Mahroos F. Validity and reliability of death certificates and vital health records in Bahrain. Eastern Mediterranean health journal, 2000, 6:661-9.

3. Better health for all. Strategic health plan. Bahrain, Health Information Directorate, Ministry of Health, 1997.

4. Musaiger AO. Diet-related chronic diseases in the Arab Gulf countries: the need for action. Ecology of food and nutrition, 1994, 32:91-4.
5. Musaiger AO. The state of food and nutrition in Bahrain. Miyadh, United Nations Children's Fund, Gulf Area Office, 1993.

6. Musaiger AO. Change in dietary habits, lifestyle and trend in diseases in the GCC countries. Bahrain medical bulletin, 1998, 20:87-90.

7. Hamadeh RR et al. Prevalence of smoking in Bahrain. Tobacco control, 1992, 1:102-6.

8. Health statistics reports 1982-1997. Bahrain, Health Information Directorate, Ministry of Health, 1982-97.

9. Statistical abstract 1996. Bahrain, Directorate of Statistics, Central Statistics Organization, 1997. 
10. The population nousing, oulldings and establishments census: 1991. Summary results, part two. Bahrain, Directorate of Statietice, Contral Statistice Organization, 1993.

11. The world health report 1997: conquering suffering, enriching numanity. Geneva, World Health Organization, 1997.

12. Hamadeh RR, Khalifa F. Avoidable risk factors of cancer in Bahrain. International journal of food science and nutrition, 1998, 49:S59-\$64.

13. Zurba FI, Al-Garf A. Prevalence of diabetes mellitus in Bahrain. Bahrain medical bulletin, 1996, 18:44-51.

14. Al-Mahroos F, McKeigue PM. High prevalence of diabetes in Bahrainis. Associations with ethnicity and raised plasma cholesterol. Diabetes care, 1998, 21:936-42.

15. Musaiger AO. Rapid assessment of dietary habits of elderly people in Bahrain. Bahrain, Ministry of Health, 1992.

16. Yacoub I et al., eds. Bahrain Family Health Survey 1995. Preliminary report. Manama, Ministry of Health and Riyadh, Counclt of Health MInIsters of GCC States, 1996.

17. Musaiger AO, Al-Roomi KA. Prevalence of risk factors for cardiovascular diseases among men and women in an
Arab Gulf community. Nutrition and health, 1997, 11:149-57.

18. Al-Mannai A et al. Obesity in Bahraini adults. Journal of the Royal Society of Health, 1996, 116:30-2, 37-40.

19. Musaiger $A O$ et al. Obesity among secondary-school students in Bahrain. $\mathrm{Nu}$. trition and health, 1993, 9:25-32.

20. Hamadeh RR. Smoking habits of primary health care physicians in Bahrain. Journal of the Royal Society of Health, 1999, 119:36-9.

21. Hamadeh RR. Smoking habits of medical students in Bahrain. Joumal of smoking-related disorders, 1994, 5:189-95.

22. Al Haddad N. Smoking among secondary male students in Bahrain. Bahrain, Family Practice Residency Programme, Ministry of Health, 1998.

23. Afifi LA. An exploratory study to investigate the determinants of health behavior towards smoking in Bahrain secondaryschool males [Dissertation], Iowa, University of lowa, 1983.

24. Lababidi N. Smoking in Bahrain boys' public secondary schools. Bahrain. Family Practice Residency Programme, Ministry of Health, 1989.

25. Hamadoh RR. Smoking habite in Bahrain, 1981-1991. Journal of the Bahrain Medical Society, 1998, 10:24-30. 